\title{
Different Shades of Nudges: Moderating Effects of Individual Characteristics and States on the Effectiveness of Nudges during a Fast-Food Order
}

\author{
Irina Dolgopolova ${ }^{1, *}$, Alessia Toscano ${ }^{2}$ and Jutta Roosen ${ }^{2}$ (1) \\ 1 Department of Marketing and Supply Chain Management, School of Business and Economics, \\ Maastricht University, 6211 LK Maastricht, The Netherlands \\ 2 Marketing and Consumer Research, School of Management, Technical University of Munich, \\ 85354 Freising, Germany; alessia.toscano@hotmail.com (A.T.); jroosen@tum.de (J.R.) \\ * Correspondence: i.dolgopolova@maastrichtuniversity.nl
}

check for updates

Citation: Dolgopolova, I.; Toscano,

A.; Roosen, J. Different Shades of

Nudges: Moderating Effects of

Individual Characteristics and States on the Effectiveness of Nudges

during a Fast-Food Order.

Sustainability 2021, 13, 13347.

https: / /doi.org/10.3390/su132313347

Academic Editors: Giovanni Sogari and Irina Dolgopolova

Received: 26 October 2021

Accepted: 29 November 2021

Published: 2 December 2021

Publisher's Note: MDPI stays neutral with regard to jurisdictional claims in published maps and institutional affiliations.

Copyright: (c) 2021 by the authors. Licensee MDPI, Basel, Switzerland. This article is an open access article distributed under the terms and conditions of the Creative Commons Attribution (CC BY) license (https:/ / creativecommons.org/licenses/by/ $4.0 /)$.

\begin{abstract}
Nudges, or subtle changes to a choice environment, are increasingly used in online food ordering platforms to improve dietary choices and reduce calorie intake. We report the results of an experiment aimed at nudging young adults to reduce calories in a fast-food order $(\mathrm{N}=994)$. The nudging interventions used were: an order assistant, a color-coded system, and a combination of the order assistant and color-coded system. We hypothesized that participants' characteristics (sex, BMI, education) and states (positive affect, negative affect, hunger) moderate the effectiveness of nudges. Our analysis shows that the effect of nudges is slightly increasing at higher BMI levels. In the combined treatment, hunger and negative affect significantly moderate the effect of nudges. We do not observe the moderating effects of participants' sex, educational level, and positive affect in any of the treatments.
\end{abstract}

Keywords: young adults; food choices; nudge; BMI; negative emotions

\section{Introduction}

Nudges, or subtle changes in the choice environment, are valuable in encouraging healthy dietary choices and reducing caloric intake [1-3]. A classic example of a nudge is rearranging food in a school cafeteria to make low-calorie options more accessible than high-calorie options, e.g., when deserts are moved from the first line to the last line [4]. After the first use in offline environments, nudges are currently being applied in digital environments as well. Digital nudges can be defined as "the use of user-interface design elements to guide people's behavior in digital choice environments" [5]. The relevance of the digital choice environment derives from the increasing number of decisions made with the help of digital technologies.

Among many decisions in the digital environment, food choices are often made using a screen interface, for example, when ordering food online. However, online choice environments are susceptible to similar biases in decision-making processes as offline environments. When it comes to food, choices are often made without elaborate decision making and are prone to the influence of situational and psychophysiological factors [6]. Situational factors include the physical surroundings of an individual during the process of choice. In contrast, psychophysiological factors refer to psychological states (e.g., moods) and physiological states (e.g., feelings of thirst or hunger) [7]. In addition, physiological states such as obesity are associated with the consumption of energy-dense foods and with experiencing more pleasure from food consumption [7].

Recently, rapid development of online-to-offline $(\mathrm{O} 2 \mathrm{O})$ delivery services raises concerns regarding food choices that are made online. Researchers $[8,9]$ point at the dangers imposed by $\mathrm{O} 2 \mathrm{O}$ systems for public health, which include the higher availability and accessibility of high-calorie foods, and reduced physical activity. Consequently, the discourse 
about obesity and possible measures to fight it is concentrated around choice architecture and nudging as potential moderators of food choice $[2,10]$. In general, nudging people to lower calorie intake with calorie labeling has proven to be an effective measure [11,12]. The effect of nutritional labeling on energy intake was assessed in a recent Cochrane review and indicated that although nutritional labeling may reduce energy intake, the results should be used with caution as the quality of most studies reviewed is relatively low [13]. However, surprisingly little attention has been paid so far to individual characteristics and states that can moderate the influence of nudges on calorie intake. In this study, we develop and test several hypotheses which assume that the effectiveness of nudges in lowering calorie intake can differ among individuals with different food consumption related characteristics and affective states. We review the scarce relevant literature and develop six hypotheses which are tested in an online experiment with digital nudges. The nudges in the experiment are implemented depending on the amount of calories in the order basket relative to the goal stated by participants prior to the order.

There is no consistent evidence on the influence of biological sex on the effectiveness of calorie labeling communications, either in the form of traditional labels or nudges. Long et al. [14] observe that women may reduce calories purchased more than men when exposed to menu calorie labeling. Still, this result is not consistent across studies included in their meta-analysis. Another evidence on possible interaction is provided by Friis et al. [15], who observe that nudges might influence women differently than men. They explain the result with potential differences between men and women when making choices. In addition, Reisch \& Sunstein [16] find that females have a slightly more positive attitude towards nudges. In addition, it was demonstrated that females use the nutritional information on labels more often than men [17] and that food decisions are of greater importance and relevance for women [18]. Thus, we develop our first hypothesis: (1) Biological sex moderates the effectiveness of nudges.

Bucher et al. [2], in a systematic review of literature related to nudging consumers towards healthier food choices, reports two studies that consider bodyweight in the analysis of nudging interventions. Both studies suggest that experiment participants react to food positioning similarly, irrespective of body weight. On the other hand, reading labels with ingredients was found to be negatively associated with body mass index (BMI) [19], and low nutritional label experience was linked to an increased likelihood of obesity [20]. Meyers et al. [21] tested whether people with higher levels of BMI are more affected by a food rearrangement (a nudge) than the normal-weight people, but their results showed no significant difference. Our following hypothesis is formulated: (2) The BMI moderates the effectiveness of nudges.

In their study of the effect of priming on healthy food choice, Forwood et al. [22] report that the effects of primes on healthy eating choices depend on participants' level of education. Under the influence of priming and hunger, more educated participants chose more fruits for a meal when being hungry compared to other participants. In addition, most studies on nutrition labels on pre-packaged goods report higher use and a better understanding of nutritional labels by people with higher educational levels [23]. This leads to our third hypothesis: (3) The effectiveness of nudges is moderated by the level of education.

Among psychological factors, emotions were identified as an essential determinant of the amount of food consumed and the energy density of this food [24]. For example, Lyman [25] demonstrated that positive emotions are primarily associated with consuming healthy foods while negative ones are associated with junk food. Patel \& Schlundt [26] found that both positive and negative emotions led to larger meals being consumed compared to a neutral emotional state. Negative emotions were also linked to higher self-rated motivations to eat [27]. In another study, positive emotions were related to higher calorie consumption and snack intake [28]. Only positive affect increased the calories consumed but negative affect had no effect in the study of Bongers et al. [29]. In general, both negative and positive emotions have been linked to increased food consumption; 
however, the evidence on positive emotions is less conclusive [30]. Hypotheses 4 and 5 are formulated as follows: (4) Positive emotions moderate the effectiveness of nudges, and (5) Negative emotions moderate the effectiveness of nudges.

Hunger was identified as an essential factor influencing calorie consumption in interaction with impulsivity [31]. Forwood et al. [22] demonstrated that the state of hunger moderates the effects of a prime on healthy eating by reducing the likelihood of purchasing fruits and vegetables. However, no study so far assessed the influence of hunger level on the effectiveness of nudging interventions. Our sixth hypothesis is as follows: (6) The effectiveness of nudges is moderated by the level of hunger.

Fast food is often discussed as being one of the reasons for overweight and obesity. Rosenheck [32] describes it as "energy-dense, poor in micronutrients, low in fiber, high in glycemic load and excessive in portion size, causing many to exceed daily energy requirements". Many researchers studied if there was a link between fast food consumption and a high BMI. The outcomes of studies and systematic reviews failed to prove a significant connection because of the difficulty of isolating the many drivers that lead to obesity [32]. Nevertheless, many researchers suggest, some more strongly than others, that there is a potential connection between rates of fast food consumption in society and increasing rates of overweight and obesity [33]. Thus, we use an ordering screen imitating the ordering screen of a fast-food restaurant.

Young adults are the focus of the study. This choice was made for several reasons. First, young adults are an age category at serious risk of gaining weight. Munt et al. [34] report that young adults are more likely to gain weight than any other age group. Second, young adults very frequently consume away-from-home food. Indeed, Larson et al. [35] report that $40 \%$ of their daily energy intake derives from eating away from home and that when eating away from home, young adults prefer fast-food restaurants. This finding is closely related to the conclusion that young adults are the age category with the highest regular fast-food consumption, consuming fast food about four times more than older adults $[33,36]$.

The overall purpose of this study is to explore nudging effects' heterogeneity among young adults when making fast food choices. The paper is organized as follows: The next section discusses the sample and the methodology of this study. Section 3 presents the data analysis and results. Section 4 concludes with the discussion and the limitations of the study.

\section{Materials and Methods}

\subsection{Participants}

The study took place in Germany in January 2019. The initial sample consisted of 1001 respondents provided by a marketing company. The study took place online and could be completed on different devices, including a personal computer or a smartphone. Participants had to complete a hypothetical food order and fill in the questionnaire. As the study concentrates on young adults, we only included subjects between 18 and 25 years old. The screening question for fast food consumption frequency aimed at filtering out non-habitual customers and rejected all subjects that consume fast food less than once a month. The sex quota maintained an equal share of females and males. Participants characteristics regarding age, sex, education, and fast-food consumption frequency are presented in Table 1. The final sample included 994 participants (7 participants were excluded due to incorrectly placed orders). 
Table 1. Participants' individual characteristics $(\mathrm{N}=994)$.

\begin{tabular}{ccccc}
\hline Variable & Description & Mean (Std. Dev.) & Min & Max \\
\hline Age & Age in years & $21.96(2.23)$ & 18 & 25 \\
\hline $\begin{array}{c}\text { Fast food } \\
\text { consumption } \\
\text { frequency }\end{array}$ & $\begin{array}{c}\text { 5-point Likert scale (from "every } \\
\text { day" to "once a month") }\end{array}$ & $3.27(1.10)$ & 1 & 5 \\
\hline Sex & 1-female, 2-male & $1.50(0.50)$ & 1 & 2 \\
\hline Education & $\begin{array}{c}\text { 1-no degree; 2-secondary general } \\
\text { school; 3-intermediate secondary } \\
\text { school; 4-(specialized) } \\
\text { grammar school }\end{array}$ & $3.64(0.62)$ & 1 & 4 \\
\hline
\end{tabular}

\subsection{Design}

The study protocol consisted of three parts: a pre-experiment questionnaire, an online fast-food order simulation, and a post-experiment questionnaire. The process and variables assessed are presented in Table 2.

Table 2. Study design.

\begin{tabular}{|c|c|c|}
\hline $\begin{array}{l}\text { Pre-Experiment } \\
\text { Questionnaire }\end{array}$ & Fast Food Order Simulation & $\begin{array}{c}\text { Post-Experiment } \\
\text { Questionnaire }\end{array}$ \\
\hline $\begin{array}{c}\text { Age } \\
\text { Fast food frequency } \\
\text { Sex } \\
\text { Height and weight (BMI) } \\
\text { Education } \\
\text { Emotions (PANAS) } \\
\text { Hunger, time from last meal } \\
\text { and its type }\end{array}$ & $\begin{array}{c}\text { Cheap talk } \\
\text { Calorie goal setting } \\
\text { Order simulation according } \\
\text { to treatment }\end{array}$ & $\begin{array}{c}\text { Diet } \\
\text { Calorie counting habit } \\
\text { Self-control scale } \\
\text { Food addiction } \\
\text { Fast food type habit } \\
\text { Social Norms Espousal } \\
\text { Emotional eating scale } \\
\text { Order satisfaction } \\
\text { Treatment satisfaction } \\
\text { Housing situation } \\
\text { Income }\end{array}$ \\
\hline
\end{tabular}

In the screening questionnaire, participants indicated their age, frequency of fast food consumption, and sex. The pre-experiment questionnaire asked participants to indicate their height and weight, which were used to calculate BMI, the level of education, the emotional state before the experiment, their level of hunger, and the time since their last meal. After that, a cheap talk instructed the participants about the upcoming task to place a food order for a one-person meal. When participants completed their food order, they were prompted to answer scales regarding their psychological characteristics and provide additional socio-demographic information.

\subsection{Treatments}

For the following analysis, only variables measured in the first questionnaire are used and we do not elaborate further on the measures identified in the second questionnaire, but they are available from authors upon request.

In the experimental treatments, a dynamic feedback system benchmarked calories in the order against a preset goal, which participants had to indicate before the food order. This goal was necessary to provide personalized nudging to each participant. We used a default option of 700 calories to inform the participants about the recommended calories per meal. After that, participants were randomly assigned to one of the four treatments: (1) no treatment, (2) the presence of an order assistant on the screen (OA), (3) the presence of the color-coded system on the screen (CCS), or (4) the presence of an order assistant and a color-coded system on the screen (OA\&CCS) (Table 3). 
Table 3. Screens presented to the participants according to treatment groups.

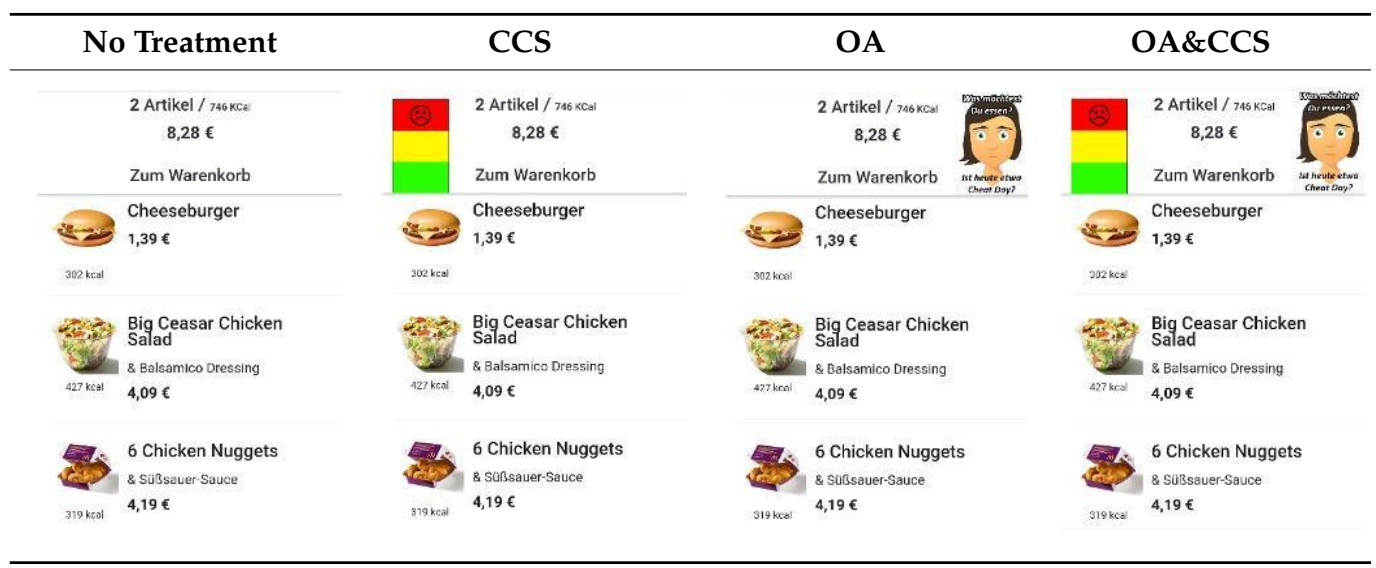

During the order, participants could choose dishes by scrolling up and down the screen. The participants had to choose their meal from a menu consisting of 19 products, including main dishes, sides, soft drinks, and a dessert. Digital nudges in the form of an OA and/or a CCS reacted to the overall amount of calories in the order (Tables 3-5). OA's facial expression changed from neutral to shocked when the number of calories in the order increased. A male or female face was randomly assigned to the participants in treatments OA and OA \& CCS. CCS consisted of a bar, where the first green level indicated the number of calories below the calorie goal, but yellow and red colors appeared on top of the green when the calorie goal was exceeded. The CCS was combined with smileys, helping with the interpretation of colors. During the order, participants could add and remove dishes according to their will and could finish their order at any time.

Table 4. $\mathrm{OA}^{\mathrm{a}}$ reactions to the number of calories in the order (an example with the default option of $700 \mathrm{kcal})$.

\begin{tabular}{|c|c|c|c|c|c|}
\hline $\begin{array}{l}\text { Amount of } \\
\text { Calories } \\
\text { Ordered }\end{array}$ & $\mathbf{0}$ & $1-700^{b}$ & $701-1050^{c}$ & $1051-1400^{d}$ & $>1400^{\mathrm{e}}$ \\
\hline $\begin{array}{c}\text { Facial } \\
\text { expression }\end{array}$ & 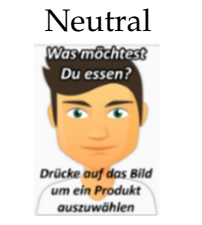 & 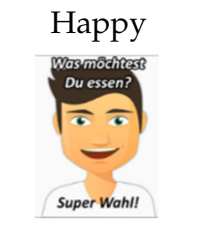 & 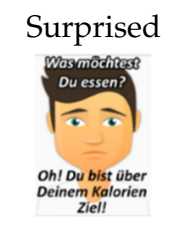 & 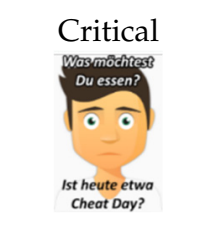 & 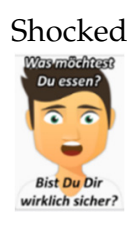 \\
\hline & 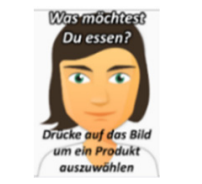 & 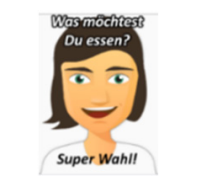 & 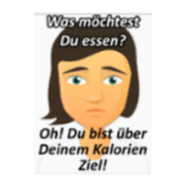 & $\begin{array}{l}\text { Wasmoothress } \\
\text { Du essen? } \\
\text { ist heute etwa } \\
\text { Cheat Day? }\end{array}$ & $\begin{array}{c}\text { Wasmocthess } \\
\text { Du essen? }\end{array}$ \\
\hline $\begin{array}{c}\text { Verbal } \\
\text { message }\end{array}$ & $\begin{array}{l}\text { Please touch } \\
\text { on a product } \\
\text { to choose it! }\end{array}$ & Great choice! & $\begin{array}{l}\text { Oh! You are } \\
\text { above your } \\
\text { calorie goal. }\end{array}$ & $\begin{array}{l}\text { Is today your } \\
\text { cheat day? }\end{array}$ & $\begin{array}{c}\text { Are you } \\
\text { sure? }\end{array}$ \\
\hline
\end{tabular}


Table 5. CCS changes depending on the number of calories in the order (an example with the default option of $700 \mathrm{kcal})$.

\begin{tabular}{|c|c|c|c|c|}
\hline $\begin{array}{c}\text { Amount of } \\
\text { Calories } \\
\text { Ordered }\end{array}$ & 0 & $1-700$ & $701-1050^{a}$ & $>1051$ \\
\hline \multirow[t]{2}{*}{ CCS colors } & & & $\odot$ & \\
\hline & & (:) & & \\
\hline
\end{tabular}

${ }^{a}$ Upper and lower limits calculated as in Table 4.

After participants submitted their orders, they were directed to the second part of the questionnaire. They answered scales measuring their level of self-control, emotional eating, food addiction, and social norm espousal. The value in Table 4 was calculated from the advised average $2000 \mathrm{kcal}$ per day, leading therefore to approximately $700 \mathrm{kcal}$ per meal (German Nutrition Society (DGE), 2015). Entering a calorie goal before placing an order can be considered as a separate intervention, however, it is an essential part of our experimental design as it is used to calculate the excess calories in the order.

\subsection{Measures}

\subsubsection{BMI}

The BMI was calculated using participants' self-reported height and weight. Participants' height was inquired with the question: "How tall are you?", where the participants had to indicate their height in centimeters. Participants' weight was assessed with the question: "What is your weight?", where the participants had to enter their weight in kilograms. BMI was calculated as BMI $=$ Weight $/(\text { Height } / 100)^{2}$.

\subsubsection{Hunger}

We assessed the hunger level with the question: "How hungry are you at the moment?". Participants rated their hunger level on a 5-point scale, anchored from 1-"not hungry at all" to 5-"very hungry." [37] The question "How many hours ago did you eat your last meal?" was included for additional control of the hunger levels. To answer this question, participants had to indicate any number of hours between 0 and 12 .

\subsubsection{Affective States}

The emotional state of the participants before the order was assessed using the German version [38] of the PANAS (Positive Affect Negative Affect Scale) [39]. The PANAS scale consists of 20 ratings regarding specific emotions where the first 10 refer to positive affect and the next 10 to negative affect. Each emotion is rated on a 5-point Likert scale: 1-very slightly or not at all; 2-a little; 3-moderately; 4-quite a bit; and 5-extremely. Mean scores were calculated for positive and negative affect [39].

\subsection{Statistical Analysis}

Our statistical approach consists of two major steps. At first, we use one-way ANOVA to test differences in calories ordered across different treatments. Second, the model presented in Equation (1) is used to test our hypotheses. The model includes main and interaction effects between nudges on the ordering screen and participants' characteristics and states:

$$
\mathrm{Cal}_{i}=\beta_{0}+\beta_{1} O A_{i}+\beta_{2} \mathrm{CCS}_{i}+\beta_{3} \operatorname{CCS} \& O A_{i}+\beta_{4} M_{i}+\beta_{5} \mathrm{OA} \times M_{i}+\beta_{6} \mathrm{CCS} \times M_{i}++\beta_{7} \operatorname{CCS} \& O A \times M_{i}+\varepsilon,
$$

where $\mathrm{Cal}$ is the number of calories in the order, $O A$ is the order assistant treatment, CCS is the color-coded system treatment, $C C S \& O A$ is the treatment including a combination of a color-coded system and an order assistant, $M$ is the moderator variable, $O A \times M$ 
is the interaction term between order assistant treatment and the moderator, $C C S \times M$ is the interaction term between color-coded system treatment and the moderator, and $C C S \& O A \times M$ is the interaction term between the treatment, which includes a combination of the color-coded system and the order assistant and the moderator. As for moderating variables, we use participants' characteristics and psychophysiological states measured before the treatment. We test if the effect of nudges on the number of calories in the order is moderated by sex, BMI, educational level, affective state, and the level of hunger. Each hypothesis is tested with a separate two-way ANOVA based on Equation (1). We use the same dependent variable, the number of calories in the fast-food order, for all the regressions. Goodness-of-fit is determined using $\mathrm{R}^{2}$. All estimations are performed using Stata 13.

\section{Results}

Table 6 summarizes descriptive statistics regarding additional measures used in the study. Participants are characterized by on average low BMI and demonstrate more positive than negative affect.

Table 6. Participants' characteristics and states $(\mathrm{N}=994)$.

\begin{tabular}{cccc}
\hline Variable & Mean (Std. Dev.) & Min & Max \\
\hline BMI & $23.53(4.82)$ & 10.89 & 70.10 \\
\hline Positive affect & $29.39(7.08)$ & 10 & 49 \\
\hline Negative affect & $18.17(7.75)$ & 10 & 43 \\
\hline Hunger & $2.17(1.06)$ & 1 & 5 \\
\hline
\end{tabular}

The calories ordered in each treatment were compared using one-way ANOVA to determine the presence of treatment effects. Participants in the OA treatment ordered $208 \mathrm{kcal}$ less than in the no treatment condition $(F=26.84, p<0.01)$. Participants who faced the CCS treatment ordered $225 \mathrm{kcal}$ less than in the no treatment condition $(F=31.96$, $p<0.01)$. In the combined OA\&CCS treatment, participants ordered $250 \mathrm{kcal}$ less than in the no treatment condition $(F=38.29, p<0.01)$.

We further proceed with estimating linear regressions, based on the general model (1) separately for each of the hypotheses. The results of the estimations are presented in Table 7 (Independent variables are standardized to avoid multicollinearity. ${ }^{* *}, * *, *$ denote significance at $p<0.01, p<0.05$, and $p<0.10$ respectively).

We do not observe significant interaction effects between sex and nudging treatments. However, significant main effects are observed, indicating that men order more calories than women. Still, when the nudges are present on the screen, both men and women react to nudges similarly, decreasing the number of calories in the order. Hypothesis 1 is not supported. Marginally significant interaction effects are observed for BMI and nudging interventions. The effectiveness of nudges is slightly amplified with increasing BMI. In addition to regression results, we plot the interaction effects (Figure 1) to aid the interpretation of moderation. Plotlines illustrate the support for Hypothesis 2, stating that the effectiveness of nudges depends on an individual's BMI.

Interaction effects between treatments and educational level are insignificant, not supporting hypothesis 3. Positive emotions do not influence the number of calories ordered (Hypothesis 4). However, negative emotions have significant main and interaction effects in the CCS \& OA treatment, partially supporting Hypothesis 5, Figure 2. Hunger has a significant positive effect on the number of calories ordered, which is an expected result. However, it also marginally interacts with the CCS \& OA treatment, suggesting that when facing the combination of a color-coded system and an order assistant on the screen, participants who are very hungry order less calories than in other treatments (Figure 3), partially supporting Hypothesis 6. 
Table 7. Regression analysis results ( $\mathrm{N}=994)$.

\begin{tabular}{|c|c|c|c|c|c|c|}
\hline \multirow[b]{2}{*}{ Variable } & \multicolumn{6}{|c|}{ Coefficients (Std. Err.) } \\
\hline & $\begin{array}{c}\text { Hypothesis } 1 \\
\text { Sex }\end{array}$ & $\begin{array}{c}\text { Hypothesis } 2 \\
\text { BMI }\end{array}$ & $\begin{array}{l}\text { Hypothesis } 3 \\
\text { Education }\end{array}$ & $\begin{array}{c}\text { Hypothesis } 4 \\
\text { Positive Affect }\end{array}$ & $\begin{array}{c}\text { Hypothesis } 5 \\
\text { Negative Affect }\end{array}$ & $\begin{array}{l}\text { Hypothesis } 6 \\
\text { Hunger }\end{array}$ \\
\hline $\mathrm{OA}$ & $-225.17(39.06)^{* * *}$ & $-231.25(39.89)^{* * *}$ & $-228.99(39.62)^{* * *}$ & $-225.43(39.97)^{* * *}$ & $-226.72(39.32)^{* * *}$ & $-232.95(39.01)^{* * *}$ \\
\hline CCS\&OA & $-247.77(39.54)^{* * *}$ & $-255.20(40.38)^{* * *}$ & $-247.74(40.13)^{* * *}$ & $-252.28(40.75)^{* * *}$ & $-252.50(39.90)^{* * *}$ & $-249.51(39.49) * * *$ \\
\hline Sex & $71.10(27.77) * *$ & & & & & \\
\hline BMI & & $81.18(32.37)^{* *}$ & & & & \\
\hline Education & & & $-49.68(27.41) *$ & & & \\
\hline Negative & & & & & $107.57(29.32) * * *$ & \\
\hline Hunger & & & & & & $135.97(27.18)^{* * *}$ \\
\hline $\mathrm{OA} \times$ Sex & $25.93(39.08)$ & & & & & \\
\hline $\mathrm{OA} \times \mathrm{BMI}$ & & $-81.79(43.33)^{*}$ & & & & \\
\hline $\mathrm{OA} \times$ Education & & & $-26.69(37.51)$ & & & \\
\hline OA $\times$ Positive & & & & $20.74(42.24)$ & & \\
\hline OA $\times$ Negative & & & & & $-53.42(39.28)$ & \\
\hline $\mathrm{OA} \times$ Hunger & & & & & & $-49.97(38.33)$ \\
\hline $\mathrm{CCS} \times \operatorname{Sex}$ & $22.56(39.27)$ & & & & & \\
\hline CCS $\times$ Education & & & $-8.65(39.87)$ & & & \\
\hline CCS $\times$ Positive & & & & $16.65(41.84)$ & & \\
\hline CCS $\times$ Negative & & & & & $-3.17(40.26)$ & \\
\hline CCS $\times$ Hunger & & & & & & $-55.54(38.78)$ \\
\hline $\mathrm{CCS} \& \mathrm{OA} \times \operatorname{Sex}$ & $35.16(39.56)$ & & & & & \\
\hline $\mathrm{CCS} \& \mathrm{OA} \times \mathrm{BMI}$ & & $-89.59(40.92) * *$ & & & & \\
\hline CCS\&OA $\times$ Education & & & $25.94(42.10)$ & & & \\
\hline CCS\&OA $\times$ Positive & & & & $3.52(40.08)$ & & \\
\hline CCS\&OA $\times$ Negative & & & & & $-158.25(41.51)^{* * *}$ & \\
\hline CCS\&OA $\times$ Hunger & & & & & & $-70.53(40.02) *$ \\
\hline Intercept & $1122.08(27.76)^{* * *}$ & $1128.77(28.39)^{* * *}$ & $1122.37(28.14)^{* * *}$ & $1122.70(28.37)^{* * *}$ & $1119.40(27.90)^{* * *}$ & $1126.05(27.71)^{* * *}$ \\
\hline $\mathrm{R}^{2}$ & 0.09 & 0.05 & 0.06 & 0.05 & 0.08 & 0.09 \\
\hline
\end{tabular}




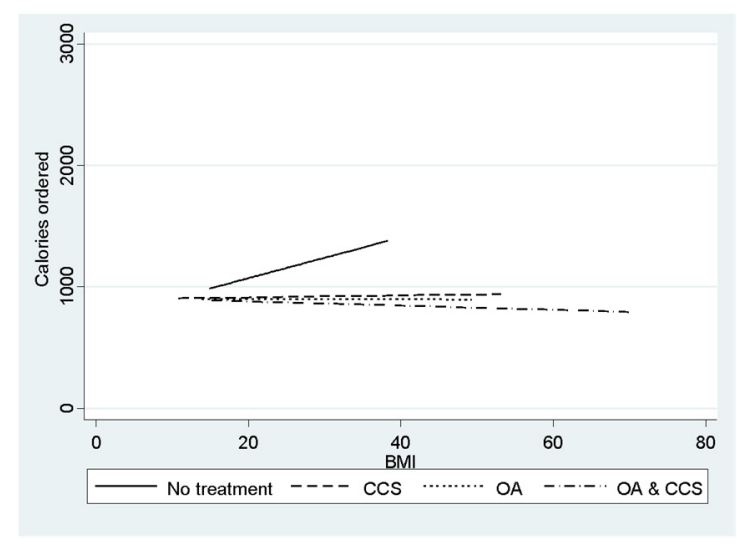

Figure 1. Interaction effects plot $(\mathrm{BMI} \times$ treatments $)$.

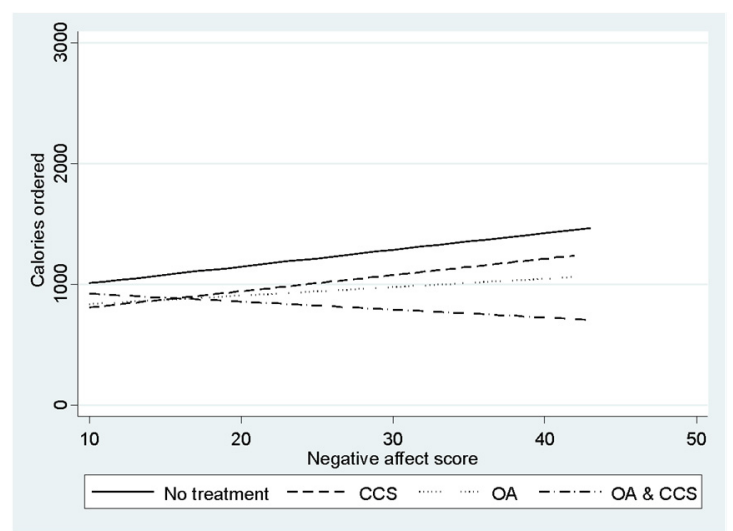

Figure 2. Interaction effects plot (Negative affect $\times$ treatments).

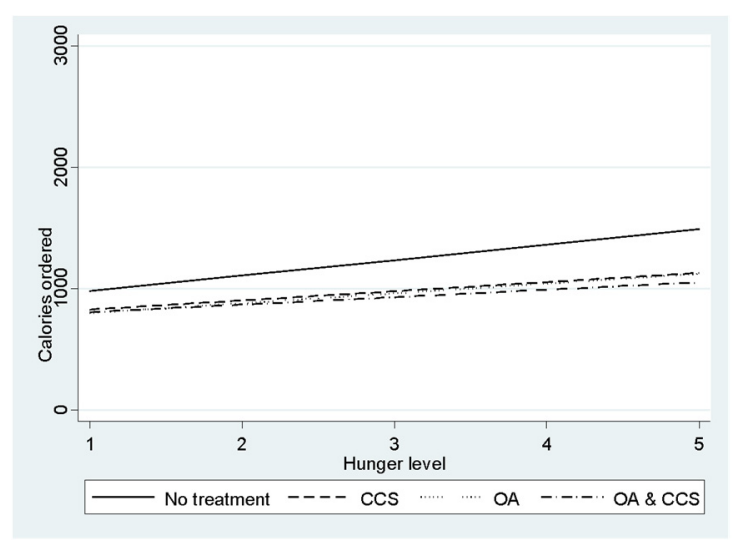

Figure 3. Interaction effects plot (Hunger $\times$ treatments).

\section{Discussion}

This study is aimed at investigating the heterogeneity of nudging effects expressed by individual characteristics and states of experiment participants. Participants experienced nudging interventions on a screen when ordering fast food. The interventions aimed at reducing the amount of calories in the order. We observe the overall significant effect of nudges in decreasing the number of calories in the fast-food order. This effect varies little for young adults with different socio-demographic characteristics and emotional states.

Biological sex has a significant main effect on the number of calories in the order. It is well established that sex differences exist in calorie consumption, with women consuming 
fewer calories than men [40], a result also found in fast food environments [41]. Our results suggest that despite differences in calorie consumption, men and women react similarly to nudges, reducing calories ordered in all nudging conditions. Although it has been observed that women tend to pay more attention to and use calorie information more than men [42], this effect might not directly translate to nudging interventions. Thus, the possible personalization of nudges in terms of biological sex will not lead to increased effectiveness.

BMI moderates the effectiveness of nudges, and the effect slightly increases at higher BMI levels. This means that nudges are more effective for the potential groups at risk, who can develop obesity at later stages in life.

Another interesting result indicates that when experiencing negative emotions, participants order fewer calories in the CCS \& OA condition. Our study provides evidence that when it comes to nudging, experiencing negative emotions can lead to lower calorie intake but only when exposed to the combination of two nudges. There is also marginal evidence supporting the hypothesis that the effectiveness of nudges depends on participants' level of hunger. Our evidence shows that when exposed to a combination of CCS \& $\mathrm{OA}$, participants order fewer calories when experiencing a higher hunger level than the control group. Interestingly, the moderating effects of hunger and negative affect manifest themselves only in the CCS \& OA condition. This condition exposes participants to two nudges simultaneously, which can be the reason for the moderation effect.

Practical implications of this study include future research directions and marketing measures. So far, very limited research has been conducted regarding digital nudges and their role in consumption. We provide evidence that the effectiveness of marketing campaigns that include nudging elements in offline shopping environments might not directly translate to online environments. Thus, further research is needed to demonstrate the differences in consumer behavior between online and offline consumption contexts when nudging is used. Moreover, this research questions the idea that the effectiveness of nudging can be increased by tailoring marketing campaigns to specific consumer segments which are defined based on sociodemographic characteristics. Our results suggest that, for example, sex and educational level are not the decisive factors for a nudge design.

This study has certain limitations. First, the experiment was hypothetical, and participants did not have to pay for and consume the food they ordered. Second, although the cheap talk was used to mitigate the problem, hypothetical bias could not be completely avoided. Another critical limitation might originate from the convenience of measuring overweight and obesity through BMI rather than using other techniques such as total body fat, which would be more accurate. Lastly, the calorie goal may present an anchor for the participants and bias the otherwise realistic nature of online food orders.

To summarize, we provide evidence that sociodemographic variables such as sex, education, and BMI and individual states such positive and negative affect and hunger have little to no moderating effect on the effectiveness of nudges. The combination of two nudging interventions on the ordering screen amplifies the moderating effect.

Author Contributions: Conceptualization, I.D.; methodology, I.D., A.T.; formal analysis, I.D., A.T.; data curation, A.T.; writing—original draft preparation, I.D., A.T.; writing—review and editing, I.D., J.R.; supervision, J.R.; project administration, J.R.; funding acquisition, J.R. All authors have read and agreed to the published version of the manuscript.

Funding: This research was funded by the enable Cluster and is catalogued by the enable Steering Committee as enable (http:/ / enable-cluster.de). This work was funded by the grant ((BMBF) FK 01EA1409A) of the German Ministry for Education and Research.

Institutional Review Board Statement: Not applicable.

Informed Consent Statement: Informed consent was obtained from all subjects involved in the study.

Data Availability Statement: Not applicable.

Conflicts of Interest: The authors declare no conflict of interest. 


\section{References}

1. Arno, A.; Thomas, S. The efficacy of nudge theory strategies in influencing adult dietary behaviour: A systematic review and meta-analysis. BMC Public Health 2016, 16, 676. [CrossRef]

2. Bucher, T.; Collins, C.; Rollo, M.E.; McCaffrey, T.; De Vlieger, N.; Van Der Bend, D.; Truby, H.; Perez-Cueto, F.J.A. Nudging consumers towards healthier choices: A systematic review of positional influences on food choice. Br. J. Nutr. 2016, 115, 2252-2263. [CrossRef]

3. Wilson, A.L.; Buckley, E.; Buckley, J.; Bogomolova, S. Nudging healthier food and beverage choices through salience and priming. Evidence from a systematic review. Food Qual. Prefer. 2016, 51, 47-64. [CrossRef]

4. Thaler, R.H.; Sunstein, C.R. Nudge: Improving Decisions About Health, Wealth and Happiness; Yale University Press: New Haven, CT, USA, 2008.

5. Weinmann, M.; Schneider, C.; Brocke, J.V. Digital Nudging. Bus. Inf. Syst. Eng. 2016, 58, 433-436. [CrossRef]

6. Cohen, D.A.; Babey, S.H. Contextual Influences on Eating Behaviors: Heuristic Processing and Dietary Choices. Obes. Rev. 2012, 13, 766-779. [CrossRef]

7. Mela, D.J. Determinants of Food Choice: Relationships with Obesity and Weight Control. Obes. Res. 2001, 9, 249S-255S. [CrossRef] [PubMed]

8. Maimaiti, M.; Zhao, X.; Jia, M.; Ru, Y.; Zhu, S. How we eat determines what we become: Opportunities and challenges brought by food delivery industry in a changing world in China. Eur. J. Clin. Nutr. 2018, 72, 1282-1286. [CrossRef]

9. Zhao, X.; Lin, W.; Cen, S.; Zhu, H.; Duan, M.; Li, W.; Zhu, S. The online-to-offline (O2O) food delivery industry and its recent development in China. Eur. J. Clin. Nutr. 2021, 75, 232-237. [CrossRef] [PubMed]

10. Vecchio, R.; Cavallo, C. Increasing healthy food choices through nudges: A systematic review. Food Qual. Prefer. 2019, 78, 103714. [CrossRef]

11. Cadario, R.; Chandon, P. Which Healthy Eating Nudges Work Best? A Meta-Analysis of Field Experiments. Mark. Sci. 2020, 39, 465-486. [CrossRef]

12. Cioffi, C.E.; Levitsky, D.A.; Pacanowski, C.R.; Bertz, F. A nudge in a healthy direction. The effect of nutrition labels on food purchasing behaviors in university dining facilities. Appetite 2015, 92, 7-14. [CrossRef]

13. A Crockett, R.; E King, S.; Marteau, T.M.; Prevost, T.; Bignardi, G.; Roberts, N.W.; Stubbs, B.; Hollands, G.; A Jebb, S. Nutritional labelling for healthier food or non-alcoholic drink purchasing and consumption. Cochrane Database Syst. Rev. 2018, 2021, CD009315. [CrossRef]

14. Long, M.W.; Tobias, D.K.; Cradock, A.L.; Batchelder, H.; Gortmaker, S.L. Systematic Review and Meta-analysis of the Impact of Restaurant Menu Calorie Labeling. Am. J. Public Health 2015, 105, e11-e24. [CrossRef] [PubMed]

15. Friis, R.; Skov, L.R.; Olsen, A.; Appleton, K.M.; Saulais, L.; Dinnella, C.; Hartwell, H.; Depezay, L.; Monteleone, E.; Giboreau, A.; et al. Comparison of three nudge interventions (priming, default option, and perceived variety) to promote vegetable consumption in a self-service buffet setting. PLoS ONE 2017, 12, e0176028. [CrossRef] [PubMed]

16. Reisch, L.A.; Sunstein, C.R. Do Europeans like nudges? Judgm. Decis. Mak. 2017, 11, 310-325. [CrossRef]

17. Sinclair, S.E.; Cooper, M.; Mansfield, E.D. The Influence of Menu Labeling on Calories Selected or Consumed: A Systematic Review and Meta-Analysis. J. Acad. Nutr. Diet. 2014, 114, 1375-1388.e15. [CrossRef]

18. Levi, A.; Chan, K.K.; Pence, D. Real Men Do Not Read Labels: The Effects of Masculinity and Involvement on College Students' Food Decisions. J. Am. Coll. Health 2006, 55, 91-98. [CrossRef]

19. Bonanno, A.; Bimbo, F.; Cleary, R.; Castellari, E. Food labels and adult BMI in Italy-An unconditional quantile regression approach. Food Policy 2018, 74, 199-211. [CrossRef]

20. Rimpeekool, W.; Yiengprugsawan, V.; Kirk, M.; Banwell, C.; Seubsman, S.-A.; Sleigh, A. Nutrition label experience, obesity, high blood pressure, and high blood lipids in a cohort of 42,750 Thai adults. PLoS ONE 2017, 12, e0189574. [CrossRef] [PubMed]

21. Meyers, A.W.; Stunkard, A.J.; Coll, M. Food accessibility and food choice. A test of Schachter's externality hypothesis. Arch. Gen. Psychiatry 1980, 37, 1133-1135. [CrossRef]

22. Forwood, S.E.; Ahern, A.; Hollands, G.; Ng, Y.-L.; Marteau, T.M. Priming healthy eating. You can't prime all the people all of the time. Appetite 2015, 89, 93-102. [CrossRef]

23. Campos, S.; Doxey, J.; Hammond, D. Nutrition labels on pre-packaged foods: A systematic review. Public Health Nutr. 2011, 14, 1496-1506. [CrossRef] [PubMed]

24. Köster, E.P.; Mojet, J. From mood to food and from food to mood: A psychological perspective on the measurement of food-related emotions in consumer research. Food Res. Int. 2015, 76, 180-191. [CrossRef]

25. Lyman, B. The Nutritional Values and Food Group Characteristics of Foods Preferred During Various Emotions. J. Psychol. 1982, 112, 121-127. [CrossRef]

26. Patel, K.; Schlundt, D. Impact of moods and social context on eating behavior. Appetite 2001, 36, 111-118. [CrossRef]

27. Macht, M.; Simons, G. Emotions and eating in everyday life. Appetite 2000, 35, 65-71. [CrossRef] [PubMed]

28. Evers, C.; Adriaanse, M.; De Ridder, D.T.; Huberts, J.C.D.W. Good mood food. Positive emotion as a neglected trigger for food intake. Appetite 2013, 68, 1-7. [CrossRef]

29. Bongers, P.; Jansen, A.; Havermans, R.; Roefs, A.; Nederkoorn, C. Happy eating. The underestimated role of overeating in a positive mood. Appetite 2013, 67, 74-80. [CrossRef]

30. Canetti, L.; Bachar, E.; Berry, E.M. Food and emotion. Behav. Process. 2002, 60, 157-164. [CrossRef] 
31. Nederkoorn, C.; Guerrieri, R.; Havermans, R.; Roefs, A.; Jansen, A. The interactive effect of hunger and impulsivity on food intake and purchase in a virtual supermarket. Int. J. Obes. 2009, 33, 905-912. [CrossRef]

32. Rosenheck, R. Fast food consumption and increased caloric intake: A systematic review of a trajectory towards weight gain and obesity risk. Obes. Rev. 2008, 9, 535-547. [CrossRef] [PubMed]

33. Bowman, S.; Vinyard, B.T. Fast food consumption of U.S. adults: Impact on energy and nutrient intakes and overweight status. J. Am. Coll. Nutr. 2004, 23, 163-168. [CrossRef] [PubMed]

34. Munt, A.E.; Partridge, S.R.; Allman-Farinelli, M. The barriers and enablers of healthy eating among young adults: A missing piece of the obesity puzzle: A scoping review. Obes. Rev. 2017, 18, 1-17. [CrossRef]

35. Larson, N.; Neumark-Sztainer, D.; Laska, M.N.; Story, M. Young Adults and Eating Away from Home: Associations with Dietary Intake Patterns and Weight Status Differ by Choice of Restaurant. J. Am. Diet. Assoc. 2011, 111, 1696-1703. [CrossRef]

36. Anderson, B.; Lyon-Callo, S.; Fussman, C.; Imes, G.; Rafferty, A.P. Fast-Food Consumption and Obesity Among Michigan Adults. Prev. Chronic Dis. 2011, 8, A71.

37. Hoddy, K.K.; Gibbons, C.; Kroeger, C.M.; Trepanowski, J.F.; Barnosky, A.; Bhutani, S.; Gabel, K.; Finlayson, G.; Varady, K.A. Changes in hunger and fullness in relation to gut peptides before and after 8 weeks of alternate day fasting. Clin. Nutr. 2016, 35, 1380-1385. [CrossRef] [PubMed]

38. Breyer, B.; Bluemke, M. Deutsche Version der Positive and Negative Affect Schedule PANAS (GESIS Panel). Zusammenstellung Sozialwissenschaflicher Items Skalen 2016. [CrossRef]

39. Watson, D.; Clark, L.A.; Tellegen, A. Development and validation of brief measures of positive and negative affect: The PANAS scales. J. Pers. Soc. Psychol. 1988, 54, 1063-1070. [CrossRef] [PubMed]

40. Arganini, C.; Saba, A.; Comitato, R.; Virgili, F.; Turrini, A. Gender Differences in Food Choice and Dietary Intake in Modern Western Societies. In Public Health—Social and Behavioral Health; Maddock, J., Ed.; InTech: Pittsburgh, PA, USA, 2012. [CrossRef]

41. Heidal, K.B.; Colby, S.E.; Mirabella, G.T.; Al-Numair, K.S.; Bertrand, B.; Gross, K.H. Cost and Calorie Analysis of Fast Food Consumption in College Students. Food Nutr. Sci. 2012, 03, 942-946. [CrossRef]

42. Gerend, M.A. Does Calorie Information Promote Lower Calorie Fast Food Choices Among College Students? J. Adolesc. Health 2009, 44, 84-86. [CrossRef] [PubMed] 